\title{
The Cost Channel of Monetary Policy Transmission
}

Andreas Westermeier *

Abstract:

Abstract: In this paper, we develop the new Keynesian Phillips curve augmented by the cost channel of monetary transmission and analyze the central bank's best monetary policy if the central bank is obliged to minimize inflation. It can be shown that a small change of the cost channel's coefficient might lead from a major increase in interest rates to a major decrease in interest rates and vice versa. Even though the optimal interest rate might change dramatically, the inflation response is of only marginal effect.

Keywords: Cost Channel, Monetary Transmission, Monetary Policy

JEL: E31, E52

DOI: $10.2478 / v 10033-010-0002-7$

\section{Introduction}

Economists always try to analyze price reactions due to changes in monetary policy. In many cases the transaction mechanism takes place within the so-called Black Box. The change in monetary policy (the input) is known as well as the price reaction (the output). But the mechanism itself remains unknown. One mechanism may be the so-called cost channel of monetary transmission. The cost-channel is located on the supply-side of the economy. The basic idea beyond is that an increase of interest rates makes credits dearer and therefore the cost of production increases as well. This increase in cost of production is passed on to the consumer via an increase in prices.

The model starts with the standard new Keynesian Phillips curve ${ }^{1}$, in which inflation is explained by the expected inflation rate and marginal costs. In accordance with Galí and Gertler (1999) as well as with Galí, Gertler and López-Salido (2001) the past inflation rate is - beside the expected (future) inflation rate - taken into account as an additional explanatory variable of inflation. Within this framework the model is augmented by introducing the interest rate as an additional cost factor in order to obtain the augmented new Keynesian Phillips curve with the cost channel. $^{2}$

In the following, we will develop the standard model and analyze the central bank's best monetary policy if the central bank is obliged to minimize inflation. It can be shown that a small change of the cost channel's coefficient might lead from a major increase in interest rate to a major decrease in interest rate and vice versa. Even though the optimal interest rate might change dramatically, the inflation response is only marginally affected.

\section{The Model}

This section introduces a model containing the interest rate as an inflation determining element. We start with a

\section{* Andreas Westermeier}

Centrum für angewandte Wirtschaftsforschung e-mail: westermeier@insiwo.de

\footnotetext{
${ }^{2}$ See for example Christiano, Eichenbaum and Evans (1997) and Chowdhury, Hoffmann and Schabert (2006).
} 
new Keynesian Phillips curve and augment this model in a second step with the cost channel. ${ }^{3}$

Three main assumptions underlie the basic model:

1. endogenous change of capital is ignored and therefore not included in the production function. ${ }^{4}$

2. the market is determined by the competition of monopolistic firms ${ }^{5}$ with sticky prices. ${ }^{6}$ Firms cannot change their prices periodically. Therefore, the price once set is fixed for an uncertain number of periods.

3. Monetary policy is reduced to setting nominal interest rates.

The two actors in this model are households maximizing their utility and firms maximizing their profits.

\subsection{Households}

The utility function $U_{t}$ of the households is given by the following equation:

$U_{t}=E \sum_{i=0}^{\infty} \beta^{i}\left|\frac{C_{t+i}^{1-\sigma}}{1-\sigma}+\frac{\gamma}{1-b}\left(\frac{M_{t+i}}{P_{t+i}}\right)^{1-\sigma}-\chi \frac{N_{t+i}^{1+\eta}}{1+\eta}\right|$

Utility is determined by the composite consumption good $C_{t}$, real money balances $M_{t} / P_{t}$ and leisure $1-N_{t}^{7} . \sigma$ is the elasticity of consumption, $b$ is the elasticity of money and $\eta$ is the elasticity of work. $\beta$ is the discount rate. The consumption good $C_{t}$ is produced by a continuum of firms, where firm $j$ produces good $j$. The consumption good $C_{t}$ can be formalized as:

$$
C_{t}=\left[\int_{0}^{1} \frac{\theta-1}{c_{j t}^{\theta}} d j\right]^{\frac{\theta}{\theta-1}}
$$

$\theta$ represents the price elasticity of demand for the individual goods. Suppose the prices for the final goods are given by $p_{j t}$, the households demand for good $j$ and the aggregate price index $P_{t}$ are given by:

$$
c_{j t}=\left(\frac{p_{j t}}{P_{t}}\right)^{-\theta} c_{i}
$$

\footnotetext{
${ }^{3}$ See Woodford (2003) and Walsh (2003) for the exact derivation of the model.

${ }^{4}$ See Cogley and Nason (1995) as well as McCallum and Nelson (1999).

${ }^{5}$ See Dixit and Stiglitz (1997).

${ }^{6}$ See Calvo (1983).

${ }^{7} \mathrm{~N}_{t}$ is the time devoted to work.
}

$$
P_{t}=\left[\int_{0}^{1} p_{j t}^{1-\theta}\right]^{\frac{1}{1-\theta}}
$$

In the beginning of period $t$ households start with the cash holding $M_{t}$. They also receive the wage income $W_{t} N_{t}$ as cash payment at the beginning of each period. Households can spend their money on consumption $P_{t} C_{t}$ or deposits $D_{t}$ yielding an interest of $R_{t}$. In addition, the households receive their deposits at period $t-1, R_{t-1} D_{t-1}$. The household's budget constraint is therefore given by:

$$
P_{t} C_{t} \leq W_{t} N_{t}-D_{t}-M_{t}+M_{t-1}+R_{t-1} D_{t-1}
$$

Households maximize their utility function 1) under the budget constraint 5 ). In equilibrium with a positive nominal interest rate, the following (Euler) equations must hold. ${ }^{8}$

$$
\begin{aligned}
& C_{t}^{-A}-\rho E_{t}\left(\frac{R_{t} P_{t}}{P_{t+1}}\right) C_{t+1}^{-A} \\
& \frac{\chi N_{t}^{m}}{C_{t}^{-\sigma}}=\frac{W_{t}}{P_{t}} \\
& \frac{\gamma\left(\frac{M_{t}}{P_{t}}\right)^{-b}}{C_{t}^{-\sigma}}=\frac{i_{t}}{1+i_{t}}
\end{aligned}
$$

Equations 6) represent the optimal intertemporal allocation of consumption. In equation 7) the marginal rate of substitution between leisure and consumption equals the real wage and in equation 8) the marginal rate of substitution between money and consumption equals the costs of holding money.

\subsection{Firms}

In the following, we focus on the firms. We assume a production function with constant economies of scale:

$$
c_{j t}=Z_{t} N_{j t}, \quad E\left(Z_{t}\right)=1
$$

$N_{j t}$ is the time devoted to work, $Z_{t}$ as an aggregated production error term, capital is - as already mentioned above - neglected. The demand curve is given by $c_{j t}=\left(\frac{p_{j t}}{P_{t}}\right)^{-\theta} C_{t} .9$ We also adopt staggered price setting. ${ }^{10}$ Only the fraction $1-\omega$ may change their prices in the period, while the fraction $\omega$ leaves the prices unchanged. The firms minimize the costs of production under the restraint of the production function. In real terms, this problem can be written as:

\footnotetext{
8 See Holman (1998) and Parker (2006)

${ }^{9}$ See equation 3.

${ }^{10}$ See Calvo (1983).
} 


$$
\min _{N_{t}}\left(\frac{W_{t}}{P_{t}}\right) N_{z}+\varphi_{\mathrm{r}}\left(\mathbf{c}_{\mathrm{jt}}-\mathrm{Z}_{\mathrm{t}} \mathrm{N}_{1 \mathrm{r}}\right)
$$

which leads to the following first order condition

$$
\varphi_{t}=m c_{t}=\frac{\frac{W_{t}}{P_{t}}}{Z_{t}}
$$

Firms chose $p_{j t}$ to maximize their profits. The profit function is given by:

Profit $=E_{z} \sum_{i=0}^{\infty} \omega^{i} \boldsymbol{\Delta}_{i, t+1}\left[\left(\frac{p_{j t}}{P_{t+1}}\right) c_{j t+1}-m c_{t+i} c_{j z+1}\right]$

The coefficient $\omega^{i}$ is the degree of price stickiness, $\left(\frac{p_{j t}}{P_{t+i}}\right) c_{j t+}$ production costs. $\Delta_{i, t+1}$ is a discount factor and can be written as $\beta^{i}\left(\frac{C_{t+i}}{C_{t}}\right)^{-\theta}$ factor and $\left(\frac{C_{t+i}}{C_{t}}\right)^{-\theta}$ with $\beta^{i}$ as a subjective discount of intertemporal consumption. Using the demand curve, $c_{j t}=\left(\frac{p_{j t}}{P_{t}}\right)^{-\theta} C_{t}$, leads to the following equation:

Profit $=E_{t} \sum_{i=0}^{\infty} \omega^{i} \boldsymbol{\Delta}_{i, t+1}\left[\left(\frac{p_{j t}}{p_{t+1}}\right)^{1-\theta}-m c_{t+i}\left(\frac{p_{j t}}{p_{t}}\right)^{-\theta}\right] c_{t+i}$

Following Walsh (2003) the above equation can be rewritten to obtain an expression for the aggregate inflation:

$$
\pi_{t}=\beta E_{t} \pi_{t+1}+\bar{k} \bar{n} c_{t}
$$

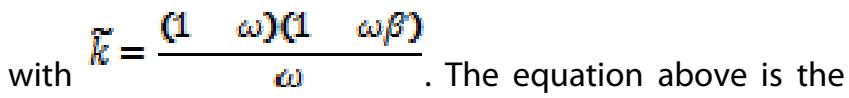
new Keynesian Phillips curve, which includes the expected inflation rate in addition to the marginal costs. The coefficient $\tilde{k}$ shows how the discount factor $\beta^{i}$ and the price stickiness factor $\omega$ influence the inflation rate $\pi$. In accordance with Galí und Gertler (1999) as well as with Galí, Gertler and López-Salido (2001) the new Keynesian Phillips curve is augmented by a backward looking element and has the following form:

$$
\pi_{t}=\left(\frac{1}{\delta}\right)\left[\beta \omega E_{t} \pi_{t+1}+(1-\lambda) \tilde{k} \hat{m} c_{t}+\lambda \pi_{t-1}\right]
$$

The assumption beyond this augmentation is that the fraction $\lambda$ of firms which might change their prices in the period simply adopt their prices by following the simple rule: $p_{j t}=\pi_{t-1} p_{t-1}^{*}$. Firms therefore adjust their prices according to the inflation rate of the last period. Equation 15) can be simplified to:

$$
\pi_{t}=\lambda_{f} E_{t} \pi_{t+1}+\lambda_{b} \pi_{t-1}+\chi \widehat{m} c_{t}
$$

\section{The Cost Channel}

Hicks (1979) was among the first to argue that the short-term interest rate might be considered a factor of costs of production. This argument was later considered by Barth and Ramey (2001), who argue that changes in the interest rate change the credit condition. ${ }^{11}$

Christiano, Eichenbaum and Evans (2005) assume that firms have to finance their production with credits. The costs of production equal the factor prices multiplied with the nominal interest rate. Since labour is the only factor of production, firms have to take out a loan of $W_{t} N_{t}$ to pre-finance the production. The nominal interest rate is given by $R_{t}$. Labour costs are therefore given by $R_{t}^{v} W_{t}$. The parameter $v$ measures the strength of the cost channel. If $v=0$ the cost channel is absent, if $v=1$ the wage bill is completely financed via credits. ${ }^{12}$ In accordance to $\begin{aligned} m c_{t}= & \frac{W_{t} / P_{t}}{Z_{t}} \text {, the real marginal costs can be written as: } \\ m c_{t} & =\frac{R_{t}^{v} W_{t} / P_{t}}{Z_{t}}=\frac{R_{t}^{v} W_{t}}{Z_{t}}=R_{t}^{v} S_{t}\end{aligned}$

By making use of a log-linear approximation, $\hat{s}_{t}+v \vec{R}_{t}$, the new Keynesian Phillips curve can be rewritten as:

$$
\pi_{t}=\lambda_{f} E_{t} \pi_{t+1}+\lambda_{b} \pi_{t-1}+\chi_{1} s_{t}+\underbrace{\chi_{1} v}_{X_{2}} \hat{R}_{t}
$$

As we can easily see in equation 18), a rise of interest rates also increases the inflation. This is contrarily to the demand side where an increase in interest rates should decrease inflation. The current empirical studies show ${ }^{13}$ that the inflationary process of increasing interest rates is only alleviated and not overcompensated.

\footnotetext{
${ }^{11}$ See also Bernanke and Gertler (1995).

${ }^{12}$ See Tillmann (2008).

${ }^{13}$ See for example Barth und Ramey (2001), Rabanal (2003), Gaiotti and Secchi (2004), Dedola and Lippi (2005), Kaufmann and Scharler (2005), Chowdhury, Hoffmann and Schabert (2006) as well as Ravenna and Walsh (2006).
} 


\section{Monetary Policy}

What is the effect of the cost channel on the monetary policy of a central bank? In the following we assume that the central bank has the objective to assure monetary stability. The primary objective of our central bank is therefore an inflation rate of almost zero. ${ }^{14}$ In the following we show the influence of the cost channel on inflation targeting in the presence of a productivity shock of $u=1$. To analyze the reaction of inflation, I approximate equation 6$)^{15}$ around a steady-state inflation of zero and obtain:

$$
\hat{c}_{t}=E_{t} \hat{c}_{t+1}-\frac{1}{\sigma}\left(\hat{R}_{t}-E_{z} \pi_{t+1}\right)+u
$$

If we neglect investment and public spending, consumption $C_{t}$ equals production $Y_{t}$. Consequently, the variation of production from the trend equals the variation of consumption from the trend, $\hat{y}_{t}=\hat{c}_{t}$. Equation 19) can be rewritten as:

$$
\sigma \hat{y}_{t}=\sigma E_{t} \hat{y}_{t+1}-\left(\hat{R}_{t}-E_{t} \pi_{t+1}\right)+u
$$

For the analysis of the optimal monetary policy, we assume that marginal costs may be represented by the output gap $\hat{H}_{t}$. If we make use of equation 18 ), we can write:

$\pi_{t}=\lambda_{f} E_{t} \pi_{t+1}+\lambda_{b} \pi_{t-1}+\gamma_{1} \hat{y}_{t}+\chi_{2} \hat{R}_{t}$

Plugging equation 20) into equation 21), we obtain: $\pi_{t}-\left(\lambda_{f}+\gamma_{1}\right) E_{t} \pi_{t+1}+\lambda_{b} \pi_{t-1}+\gamma_{1} E_{t} \hat{y}_{t+1}-\left(\gamma_{1}-\chi_{2}\right) \widehat{R}_{t}+\gamma_{1} u$

Since the central banks objective is zero inflation, we only analyze the relationship between $\vec{R}_{t}$ and $u$ and assume that the other terms equal zero. In the equilibrium the following equation must hold $\left(\gamma_{1}-\gamma_{2}\right) \bar{R}_{t}=\gamma_{1} u$. Without the cost channel the equation would be only $\gamma_{1} \hat{R}_{z}=\gamma_{1} u$. Due to the cost channel the central bank has to raise the interest rate higher without the cost channel, as long as $V_{1}>\chi_{2}$. The

\footnotetext{
${ }^{14}$ For example the European Central Bank is obliged to assure an inflation rate of below $2 \%$. Ravenna and Walsh (2006) show that it is not possible to close the output gap and to assure an inflation rate of zero simultaneously if the central bank is obliged to minimize the output gab and the inflation. In the model setting of Surico (2008) multiple equilibria are possible if the central bank assigns some positive weight to the output gap. In the following we neglect the output gap and concentrate only on the inflation rate.

${ }^{15}$ Equation 6 is given by $C_{t}^{-\sigma}=\beta E_{t}\left(\frac{R_{t} P_{t}}{P_{t+1}}\right) C_{t+1}^{-\sigma}$.
}

required change in interest rates equals $\frac{\gamma_{1}}{\gamma_{1}-\chi_{2}}$. The optimal change in interest rates in dependence of the cost channel is shown by the following figure.

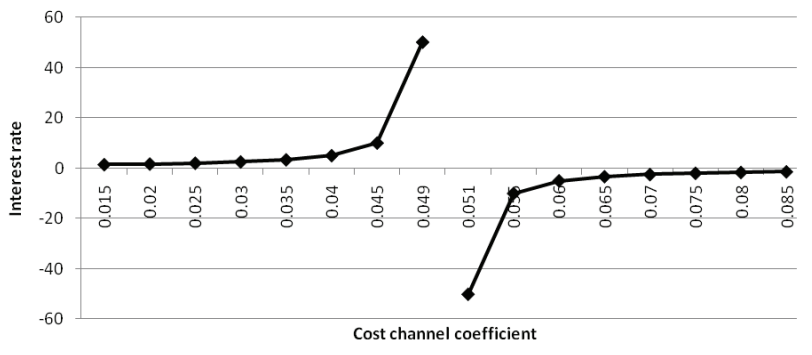

Figure 1: Optimal interest rate

We assume $\gamma_{1}=0,05$ and vary the cost channel coefficient $\chi_{2}$ between 0,015 and 0,085 . If the cost channel coefficient is 0,015 , an interest rate change of about $1,43 \%$ is required to assure an inflation rate of zero. With an increasing cost channel coefficient, the optimal interest rate change also increases and is almost infinity if the cost channel approaches 0,05 . But as soon as the cost channel coefficient is greater than $\gamma_{1}$ the optimal interest rate change turns out to be negative. Starting with an negative interest rate of almost infinity, the optimal interest rate change increases with an increasing cost channel coefficient and is about $-1,43 \%$ if the cost channel coefficient is 0,085 . Because of $\gamma_{1}-\chi_{2}$ as misspecification of the cost channel coefficient, the inflation is only influenced slightly. Suppose that the cost channel coefficient is 0,049 and $\gamma_{1}$ is 0,05 . The optimal interest rate change would be $50 \%$. But if we assume a cost channel coefficient of 0,051 , the central bank would set an interest rate change of $-50 \%$. Due to $\gamma_{\mathbf{1}}-\chi_{\mathbf{2}}$ the inflation in the first case is decreased by 0.05 percentage points, while in the second case the inflation is increased by 0.05 percentage points and therefore only marginally affected.

The central bank therefore should rather set a lower interest rate than the optimal interest rate. As long as the estimated cost channel coefficient is close to the real cost channel coefficient, the optimal interest rate would evokes a rather small inflation, but with an increasing difference between the estimated cost channel coefficient and the real cost channel coefficient the interest rate increases. A lower interest rate smoothes this effect. We assume $\gamma_{1}=0,4$, the real $\chi_{2}=0,5$ and $u=0,2$. The optimal interest rate would therefore be $0,8 \%$. In the following figure, we show how the inflation 
rate is affected if the central bank chooses different interest rates and the cost channel coefficient varies between 1 and 0 .

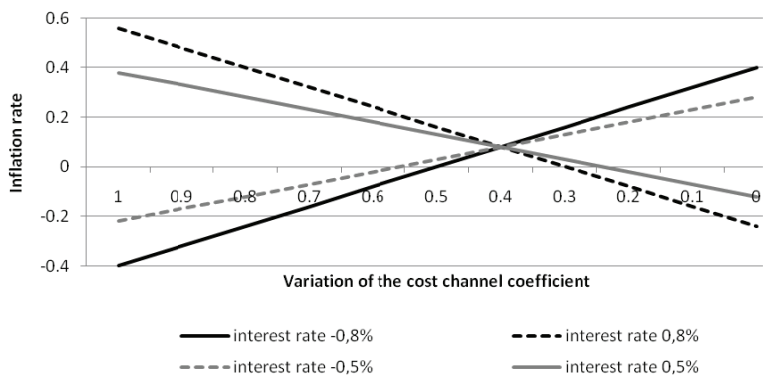

Figure 1: Inflation rate and different interest rates

If $\chi_{\mathbf{2}}=0, \mathbf{5}$, the central bank should choose an interest rate of $-0,8 \%$ to obtain an inflation rate of zero. If the central bank assumes a cost channel coefficient of 0,5 , but the real cost channel coefficient is different from 0,5 , the inflation rate increases with the difference between the real cost channel coefficient and the assumed cost channel coefficient. ${ }^{16}$ The smaller the interest rate, the smaller the inflation rate. Even though a small interest rate does not lead to zero inflation if the real and the assumed cost channel coefficient are identical, the inflation rate is minimized if the real and the assumed cost channel coefficient are different. ${ }^{17}$

\section{Results}

We used the new Keynesian Phillips Curve to analyze the optimal monetary policy if the central bank objective is an inflation of zero. The optimal interest rate to assure zero inflation is rather small if the difference between $\gamma_{1}$ and $X_{2}$ is rather big and increases with an increasing $X_{2}$. As soon as $\chi_{2}$ becomes greater than $\gamma_{1}$ the optimal interest rate changes dramatically from positive to negative. Even though the optimal interest rate might change dramatically if $X_{2}$ is close to $\gamma_{1}$ a misspecification of the cost channel and therefore a "wrong" interest rate only influences the inflation rate slightly and therefore a small deviation from a zero inflation rate occurs. The central bank should rather set a small interest rate in order to smooth the inflation rate caused by a "wrong" optimal interest rate. ㅁ.

\footnotetext{
${ }^{16}$ In our scenario the assumed cost channel coefficient is 0,5 and the real cost channel coefficient varies between 1 and 0 .

${ }^{17}$ Tillmann (2009) arrives through a different model setting to the same conclusion. Under uncertainty the central bank sets interest rate less aggressively than under certainty.
}

\section{References}

Bart, M. J. und Ramey, V. A. (2001), "The Cost Channel of Monetary Transmission", NBER Macroeconomics Annual 16, 199-240, MIT Press, Cambridge, MA.

Bernanke, B. S. und Gertler, M. (1995), "Inside the Black Box: The Credit Channel of Monetary Policy Transmission", The Journal of Economic Perspectives, 9, 27-48.

Calvo, G. A. (1983), "Staggered prices in a utility maximizing framework", Journal of Monetary Economics, 12, 383-398.

Chowdhury, I.; Hoffmann, M. und Schabert, A. (2006), "Inflation dynamics and the cost of monetary transmission", European Economic Review, 50, 955-1016.

Christiano, L. J.; Eichenbaum, M. und Evans, C. L. (1997), "Sticky price and limited participation models of money: a comparison", European Economic Review, 41, 1201-1249.

Cogley, T. und Nason, J. M. (1995), "Output Dynamics in Real-BusinessCycle Models", American Economic Review, 85, 492-511.

Dedola, L. und Lippi, F. (2005), "The Monetary Transmission Mechanism: Evidence from the Industries of five OECD Countries", European Economic Review, 49, 1543-1569.

Gaiotti, E. und Secchi, A. (2004), "Is there a cost channel of monetary policy transmission? An investigation into the pricing behaviour of 2000 firms", Temi di discussione (Economic working paper) 525, Banca d'Italia.

Galì, J. und Gertler, M. (1999), "Inflation dynamics: A structural econometric analysis", Journal of Monetary Economics, 44, 195-222.

Galì, J.; Gertler, M. und López-Salido, J. D. (2001), “European Inflation dynamics", European Economic Review, 45, 1237-1270.

Hicks, J. R. (1979), "Is Interest the Price of a Factor of Production?", In Time, Uncertainty and Disequilibrium, edited by M. J. Rizzo, 51-63, D.C. Heath and Co., Lexington, MA.

Holman, J. A. (1998), "GMM Estimation of a Money-in-the-UtilityFunction Model: The Implication of Functional Forms", Journal of Money, Credit and Banking, 30, 679-698.

Kaufmann, S. und Scharler, J. (2005), "Financial Systems and the Cost Channel Transmission of Monetary Policy Shocks", Working Paper 116, OeNB.

McCallum, B. T. und Nelson, E. (1999), "An Optimizing IS-LMSpecification for Monetary Policy and Business Cycle Analysis", Journal of Money, Credit and Banking, 21, 296-316.

Parker, J. A. (2006), "Euler Equations", unpublished working paper, Princeton University.

Rabanal, P. (2003), "The Cost Channel of Monetary Policy: Further Evidence for the United States and the Euro area", IMF Working Paper 03/149, IMF.

Ravenna, F. und Walsh, C. E. (2006), "Optimal monetary policy with the cost channel", Journal of Monetary Economics, 53, 199-216.

Roberts, J. M. (1995), "New Keynesian Economics and the Phillips Curve", Journal of Money, Credit and Banking, 27, 975-984.

Surico, P. (2008), "The Cost Channel of Monetary Policy and Indeterminacy", Macroeconomic Dynamics, 12, 724-735.

Tillmann, P. (2008), "Do interest rates drive inflation dynamics? An analysis of the cost channel of monetary transmission", Journal of Economic Dynamics and Control, 32, 2723-2744.

Tillmann, P. (2009), "Optimal Monetary Policy with an Uncertain Cost Channel", Journal of Money, Credit and Banking, 41, 885-906.

Walsh, C. E. (2003), Monetary Theory and Policy, 2. Auflage, MIT Press, Cambridge, MA.

Woodford, M. (2003), Interest and Prices: Foundations of a Theory of Monetary Policy, Princeton University Press, Princeton, NJ. 